\title{
Cooperative breeding in the endemic Madagascan Chabert's Vanga Leptopterus chabert
}

\author{
Masahiko NAKAMURA $^{1, \#}$, Takayoshi OKAMIYA ${ }^{1}$, Masaru HASEGAWA ${ }^{2}$ and Masami HASEGAWA ${ }^{3}$ \\ ${ }^{1}$ Laboratory of Animal Ecology, Department of Biology, Joetsu University of Education, 1 Yamayashiki-machi, \\ Joetsu, Niigata 943-8512, Japan \\ ${ }^{2}$ Graduate School of Life and Environmental Sciences, University of Tsukuba, Tsukuba, 1-1-1 Tennoudai, Tsukuba, \\ Ibaraki 305-8572, Japan \\ ${ }^{3}$ Department of Biology, Faculty of Science, Toho University, Funabashi, Chiba 274-8510, Japan
}

\section{ORNITHOLOGICAL SCIENCE \\ (c) The Ornithological Society of Japan 2009}

\begin{abstract}
The family Vangidae provides one of the most striking examples of adaptive radiation in the Madagascan avifauna, nevertheless, basic information on the breeding biology of many species remains lacking. To examine the breeding system of the endemic Madagascan Chabert's Vanga Leptopterus chabert, we studied the contributions made by adults to nest building, incubating, brooding, and feeding the young at six nests. The study was conducted during November and December in 1999, 2000, and 2005 at Ankarafantsika Strict Nature Reserve. During the nest-building stage, two adults (perhaps a heterosexual pair) delivered nest materials. Two adults participated in incubating and brooding. During the nestling period, several (3-4) adults delivered food (mainly bees, dragonflies, and moths) to the nestlings at two nests. They also mobbed animals that approached the nest. During the post-fledging period, several (3-4) adults fed the fledglings in two family groups. These observations suggest that Chabert's Vangas are cooperative breeders in which several adults feed the young of one brood.
\end{abstract}

Key words Breeding biology, Chabert's Vanga, Cooperative breeding, Madagascar
The Chabert's Vanga Leptopterus chabert belongs to the family Vangidae, which contains 14 (Langrand 1990) or 19 species (Yamagishi et al. 2001), and nearly all of which are endemic to Madagascar. Chabert's Vanga is a small species with an area of bright blue bare skin around the eye (Fig. 1a). It is widely distributed in Madagascar, except in the Central Plateau, occurring in secondary-growth forests at elevations between sea level and 1,800 m (Rand 1937; Langrand 1990). Chabert's Vangas feed on small invertebrates by gleaning and hovering along small branches in the canopy, and they frequently hang upside down when gleaning (Appert 1970; Langrand 1990; Yamagishi \& Eguchi 1996). Although their foraging ecology has been documented, little is known about their breeding ecology because they nest in tree tops, and because their movements are very fast.
Appert (1970) was the first to describe various aspects of the biology of Chabert's Vanga during the non-breeding and breeding seasons. He observed four nests, described biparental care, and observed cooperative breeding at one nest, including two birds participating equally in nest construction and two females feeding an incubating male (Appert 1970). Nesting occurs from August to October, and the clutch consists of three eggs (Appert 1970; Langrand 1990). However, neither the relative contributions of males and females, nor detailed observations during the different phases of reproduction have been described. The aims of this study were therefore: (1) to provide more detailed information on the breeding biology of Chabert's Vanga, and (2) to determine the breeding system by evaluating the parental investment of males and females throughout the reproductive cycle.

\# Corresponding author, E-mail: masahiko@juen.ac.jp 


\section{STUDY AREA AND METHODS}

This study was conducted in the eastern part of Ankarafantsika Strict Nature Reserve (Ampijoroa Forest Station, $16^{\circ} 15^{\prime} \mathrm{S}, 46^{\circ} 48^{\prime} \mathrm{E}$, ca. $200 \mathrm{~m}$ above sea level, about $110 \mathrm{~km}$ southeast of Mahajanga), from October to December 1999, 2000, and 2005. The eastern part of the reserve contained villages, forest stations, and campsites, around which tall trees (Eucalyptus sp., Tamarindus indica and Hura crepitans) had been planted.

In order to locate nests, we walked along trails at random from 0500 to 1000 almost every day. Six nests were found and designated as nests A to F. We identified the scientific name of the nesting trees. Their heights above the ground were measured. The diameter at breast height (DBH) of each nest tree was also recorded. When we located individuals, we recorded their positions and behaviors on a map. Males and females are similar in appearance (Langrand 1990), thus we were unable to determine their sex in the field. However, we were able to recognize different individuals attending a nest based on variation in the shape and color of the eye-ring, and the shape of the tail tip. Individuals were designated by letter codes based on their nest, for example: Aa and $\mathrm{Ab}$ in nest $\mathrm{A}, \mathrm{Ba}$ and $\mathrm{Bb}$ in nest $\mathrm{B}$.

We found one young bird (unknown sex) that had fallen to the ground from its nest tree on 13 December 2000. It was weighed to the nearest $0.1 \mathrm{~g}$ using an electronic balance, and its bill, wing, tarsus and tail lengths were all measured to the nearest $0.1 \mathrm{~mm}$ using calipers.

To examine the relative contributions of each individual to reproductive effort, we studied the following activities: (1) nest building, (2) egg laying and clutch size, (3) time budgets of incubation (percentage of time that individuals spent incubating), (5) feeding frequency (times/h/brood) and duration, (6) nestling diet. An incubation session was defined as having begun when a focal individual began incubating eggs and as having ended when that individual left the nest. Similarly, a brooding session was defined as starting when a focal individual began brooding nestlings and as ending when that individual left the nest.

Direct observations were made using a $20 \times$ spotting scope, and indirect observations were made with a SONY video Hi8 camera (CCD-TRV92) from a vantage point that allowed a good view of the nest $(10-20 \mathrm{~m})$. Direct and indirect observations were usu- ally made between 0500 and 1100 , sometimes from 0500 to 1700 . Nests were visited at three-day intervals in order to examine breeding schedules. We observed nests for a total of $112 \mathrm{~h}$ (direct observations for $66 \mathrm{~h}$ and indirect observations for $46 \mathrm{~h}$ ). Data from both direct and indirect observations were combined for the analysis.

All statistical tests were conducted with StatView 5.0 (SAS 1998). Mean values in the text are reported with standard errors $( \pm \mathrm{SE})$.

\section{RESULTS}

\section{1) Nests}

Chabert's Vanga nests were found in tree forks (Fig. 1b) or on horizontal branches (Fig. 1c), usually located $11-16 \mathrm{~m}$ above the ground (see Table 1). Nests were bowl-shaped and consisted of lichens and vegetable fibers, covered with spider webs. Nests appeared distributed randomly, approximately $200 \mathrm{~m}$ apart, with no evidence of coloniality, no other nests were found around nests A-F.

\section{2) Nest building}

We observed nest-building behaviors at two nests (A and D) on 98 occasions over nine hours (data were pooled for the two nests). Two birds participated in nest building at nests $\mathrm{A}$ and $\mathrm{D}$. At nest A, adult Aa brought material on 24 occasions (54.5\%), while adult $\mathrm{Ab}$ brought material on 20 occasions (45.5\%), within four hours. Similarly, at nest D, adult Da brought material on 26 occasions $(48.1 \%)$, compared to 28 occasions $(51.9 \%)$ by adult $\mathrm{Db}$ within five hours. Assuming that two adults were male and female and they participated equally in the nest building, there was no significant bias between them at either nest $\mathrm{A}$ or $\mathrm{D}$ (nest $\mathrm{A}: \mathrm{G}=0.18, \mathrm{P}=0.67$. nest $\mathrm{D}$ : $\mathrm{G}=0.04, \mathrm{P}=0.85$ ).

Nest-building was observed at nest A on 21 November 1999, at nest B on 28 October 2000, at nest D on 3 November 2005 and at nest E on 13 October 2005.

\section{3) Egg laying and clutch size}

By using a mirror attached to an extendible pole, we were able to observe that nest A contained three eggs on 2 December 1999. The eggs had a dull bluish-green base color, stippled with small olivebrown spots. We were unable to determine the clutch sizes in the other nests because they were too high to check. Nests C and E were each observed to contain 

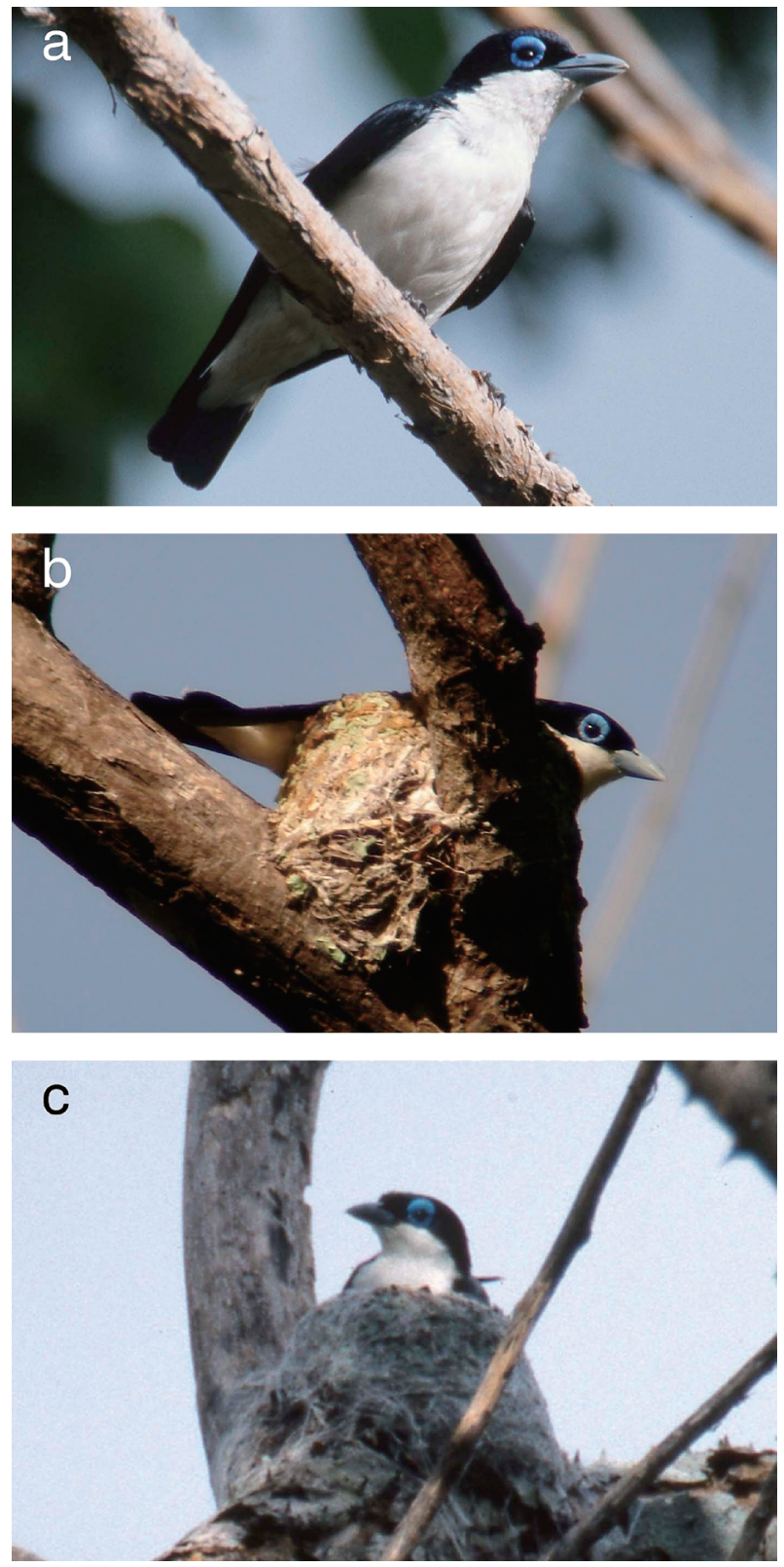

Fig. 1. Chabert's Vanga Leptopterus chabert (a), nests in a tree fork (b) and on a horizontal branch (c). Photos by Masahiko Nakamura.

three nestlings. It seems likely that three is the typical clutch size for this species.

\section{4) Incubation}

At nests $\mathrm{A}$ and $\mathrm{D}$, two individuals took turns incubating (Fig. 2). On some days (e.g. 29 November and 5 December at nest $\mathrm{D}$ ), adult $\mathrm{Db}$ incubated longer than adult Da (Fig. 2). However, the differences in the lengths of the incubation sessions between the
Table 1. Summary of nest tree (scientific name), nest height ( $\mathrm{m}$ above the ground), and DBH (diameter at breast height) at six nests in Chabert's Vangas.

\begin{tabular}{cclcc}
\hline Nest & Study year & Nest tree & $\begin{array}{c}\text { Height } \\
(\mathrm{cm})\end{array}$ & $\begin{array}{c}\text { DBH } \\
(\mathrm{m})\end{array}$ \\
\hline A & 1999 & Hura crepitans & 11 & 45 \\
$\mathrm{~B}$ & 2000 & Eucalyptus sp. & 14 & 45 \\
$\mathrm{C}$ & 2000 & Tectonia grandis & 15 & 34 \\
$\mathrm{D}$ & 2005 & Tectonia grandis & 16 & 36 \\
$\mathrm{E}$ & 2005 & Gmelina sp. & 12 & 49 \\
$\mathrm{~F}$ & 2005 & Gmelina sp. & 13 & 49 \\
\hline
\end{tabular}

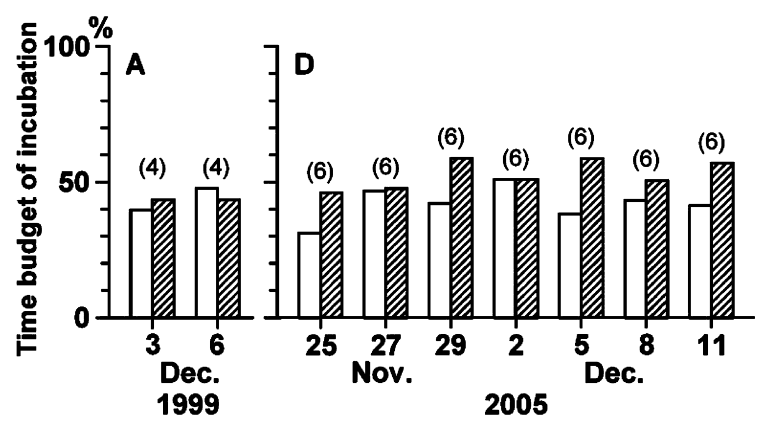

Fig. 2. Incubation time budgets of two adult Chabert's Vangas at two nests. Open bars represent Adult a; hatched bars represent Adult b. Observation times (hours) each day are given in parentheses.

Table 2. Comparison of incubation sessions ( $\mathrm{min}$ ) between a pairs of adults ( $a$ and $b$ ) at two nests. Significant differences with two-tailed Mann-Whitney U-test.

\begin{tabular}{|c|c|c|c|c|c|c|}
\hline \multirow{2}{*}{ Nest } & \multicolumn{2}{|l|}{ a } & \multicolumn{2}{|l|}{$\mathrm{b}$} & \multirow[b]{2}{*}{$\mathrm{z}$} & \multirow[b]{2}{*}{$\mathrm{P}$} \\
\hline & mean $\pm \mathrm{SE}$ & $\mathrm{N}$ & mean $\pm \mathrm{SE}$ & $\mathrm{N}$ & & \\
\hline A & $19.4 \pm 6.2$ & 7 & $12.2 \pm 4.5$ & 6 & 0.64 & 0.52 \\
\hline D & $17.2 \pm 1.2$ & 57 & $20.3 \pm 1.5$ & 55 & 1.28 & 0.20 \\
\hline
\end{tabular}

two adults did not differ significantly at either of these two nests (Table 2).

The exact period of incubation remains unknown because breeding attempts at the two nests failed before the eggs hatched.

\section{5) Feeding frequency and duration}

At nest B, the three nestlings were fed by three different adults seven times per hour on 24 November ( 3 h), 10 times per hour on 27 November $(3 \mathrm{~h})$, and 12 times per hour on 5 December 2000 ( $2 \mathrm{~h})$. When the Crested Drongo Dicrurus forficatus, the Sickle-billed 
Vanga Falculea palliata, and chameleons approached the nest, all three adults mobbed them, uttering alarm calls and snapping their beaks.

Adults were found incubating eggs at nest B on 9 and 20 November, and brooding nestlings on 22 November. The three young left the nest on 7 December. Assuming that the eggs hatched on 21 November, the nestling period (i.e. the time from hatching to leaving the nest) lasted for 16 days. We found one young (unknown sex) that had fallen to the ground from the nest tree on 13 December. It weighed $16.1 \mathrm{~g}$, and measured: wing length, $57.5 \mathrm{~mm}$; tail length, 13.8 $\mathrm{mm}$; tarsus length, $16.6 \mathrm{~mm}$; bill length, $9.9 \mathrm{~mm}$; bill width, $5.9 \mathrm{~mm}$; bill height, $5.5 \mathrm{~mm}$. We released it after measuring it.

At nest $\mathrm{E}$, one of the three nestlings remained in the nest and two were near the nest on 20 November 2000. From 0800 to 1000 on 20 November, four adults fed the individual in the nest 26 times and they delivered food to two young near the nest 34 times. All four adults mobbed Crested Drongo, Sickle-billed Vanga and the Sakalava Weaver Ploceus sakalava that approached the nest.

After fledging, the young remained near their nest tree, and the adults continued to feed them for at least seven days at nest $\mathrm{B}$ and for eight days at nest $\mathrm{E}$. However, we do not know the exact duration of postfledging parental care.

During the post-fledging period, we observed two family groups. On 21 November 1999, one family group consisted of three adults and two young; all three of the adults were seen to feed the young. On 14 November 2005, a second family group was observed near nest $\mathrm{F}$, consisting of three adults and one young; again all three adults fed the young.

\section{6) Nestling diet}

During the course of four hours of direct observation at nest B, we observed 40 prey items being fed to the nestlings. Parents frequently masticate prey before offering it to their nestlings and feeding is often very brief, making it difficult to identify all prey. However, we were able to identify 31 food items, these mainly consisted of bees (29.0\%), dragonflies $(16.1 \%)$, and moths $(16.1 \%)$. Other items included flies $(9.7 \%)$, adult antlions (9.7\%), horse flies $(9.7 \%)$, termites $(3.2 \%)$, crane flies $(3.2 \%)$, and butterflies $(3.2 \%)$.

\section{DISCUSSION}

During our studies of Chabert's Vanga at the nest, we observed two adults (perhaps a heterosexual pair) participated equally in nest construction and incubation (Fig. 2 and Table 2). However, during the nestling and the post-fledging periods, several (3-4) adults participated in caring for the young. Each of these adults mobbed animals that approached the nest. It seems that parents were being aided by helpers in various nesting activities, as is the case in certain other vangid species, such as the Rufous Vanga Schetba rufaa (Yamagishi et al. 1995; Eguchi et al. 2002) and the White-headed Vanga Leptopterus viridis (Nakamura et al. 2001). Appert (1970) reported that two adult Chabert's Vangas carried nesting material to the nest and incubated the eggs. He also reported that two females fed an incubating male. He presumed that the bird with the broader eye-ring was the male. We were unable to determine sex based on eye-ring differences and did not observe incubating individuals being fed. However, we did observe up to four adults participating in caring for one brood.

Birds species in which social groups of at least three individuals contribute to offspring care at a single nest are defined as cooperative breeders (Ekman et al. 2004). By far the most common form of cooperative breeding in birds is the 'helper-at-the-nest' type, in which younger, non-breeding individuals provide food for the young of a monogamous breeding pair, and also aid in sentinel duties or territorial defense (Smith 1990). Helpers are usually the male offspring of at least one of the breeders (Brown 1987; Ligon 1999). In this study of Chabert's Vanga, we found four family groups in each of which several adults took part in caring for the young and mobbing animals approaching the nest, confirming that Chabert's Vanga is a systematically cooperative breeding species. In order to describe the social structure of Chabert's Vanga in more detail, further nest observations, and analyses of kinship among group members, and of the relationships between pairs, are necessary.

\section{ACKNOWLEDGMENTS}

We are grateful to the Government of the Republic of Madagascar for providing permission to conduct research in Ankarafantsika Strict Nature Reserve. We are also grateful to Dr. Satoshi Yamagishi and the staff of the Botanical and Zoological Park of Tsimbazaza for their cooperation in this study. Our hearty thanks go also to the staff of ANGAP for accom- 
modation and facilities at Ampijoroa Forest Station. We thank Drs. Shigeki Asai and Taku Mizuta for their assistance in the field. We also express our thanks to two anonymous reviewers for their many constructive comments and suggestions. This study was supported by a Grant-in-Aid for Scientific Research (A) of the Ministry of Education, Science, Sports and Culture (No.11691183) and by a Grant-in-Aid for Scientific Research (B) of the Japan Society for the Promotion of Science (No.17405008).

\section{REFERENCES}

Appert O (1970) Zur Biologie der Vangawürger (Vangidae) südwest-Madagaskars. Orn Beob 67: 101-133.

Brown JL (1987) Helping and communal breeding in birds. pp 15-25. Princeton Univ Press, Princeton.

Eguchi K, Yamagishi S, Asai S, Nagata H. \& Hino T (2002) Helping does not enhance reproductive success of cooperatively breeding rufous vanga in Madagascar. J Anim Ecol 71: 123-130.

Ekman J, Dickinson JL, Hatchwell BJ \& Grieser M (2004) Delayed dispersal. In: Koenig WD \& Dickinson JL (eds) Ecology and evolution of cooperative breeding in birds. pp 35-47. Cambridge Univ Press, Cambridge.

Langrand O (1990) Guide to the birds of Madagascar. pp 290-302. Yale Univ Press, New Haven and Lon- don.

Ligon JD (1999) The evolution of avian breeding systems. pp 259-286. Oxford Univ Press, Oxford.

Nakamura M, Yamagishi S \& Nishiumi I (2001) Cooperative breeding of the White-headed Vanga Leptopterus viridis, an endemic species in Madagascar. $\mathrm{J}$ Yamashina Inst Ornithol 33: 1-14.

Rand AL (1936) The distribution and habits of Madagascar birds. Bull Amer Mus Nat Hist 72: 143-499.

SAS (1998) StatView for Macintosh, version 5.0. SAS Institute Inc, Cary, North Carolina.

Smith JNM (1990) Summary. In: Stacey PB \& Koenig WB (eds.) Cooperative breeding in birds: long-term studies of ecology and behavior. pp 593-611. Cambridge Univ Press, Cambridge.

Yamagishi S \& Eguchi K (1996) Comparative foraging ecology of Madagascar vangids (Vangidae). Ibis 138: 283-290.

Yamagishi S, Urano E \& Eguchi K (1995) Group composition and contributions to breeding by Rufous Vangas Schetba rufaa in Madagascar. Ibis 137: 157-161.

Yamagishi S, Honda M, Eguchi K \& Thorstrom R (2001) Extreme endemic radiation of the Malagasy Vangas (Aves: Passeriformes). J Mol Evol 53: 39-46. 